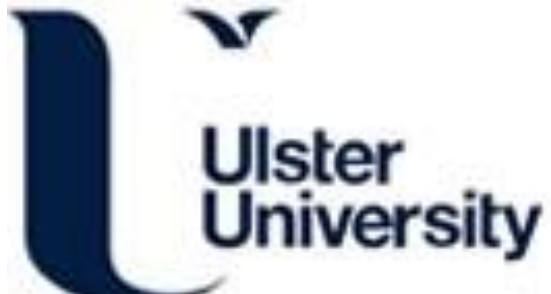

\section{Phthalocyanine-loaded nanostructured lipid carriers functionalized with folic acid for photodynamic therapy}

Oshiro-Junior, J. A., Rillo Sato, M., Isadora Boni, F., Macena Santos, K. L., Thiago de Oliveira, K., Marise de Freitas, L., Raquel Fontana, C., Nicholas, D., McHale, A. P., Callan, J., \& Chorilli, M. (2020). Phthalocyanineloaded nanostructured lipid carriers functionalized with folic acid for photodynamic therapy. Materials Science and Engineering: C, 108(110462). https://doi.org/10.1016/j.msec.2019.110462

Link to publication record in Ulster University Research Portal

\section{Published in:}

Materials Science and Engineering: C

Publication Status:

Published (in print/issue): 31/03/2020

DOI:

10.1016/j.msec.2019.110462

\section{Document Version}

Author Accepted version

\section{General rights}

Copyright for the publications made accessible via Ulster University's Research Portal is retained by the author(s) and / or other copyright owners and it is a condition of accessing these publications that users recognise and abide by the legal requirements associated with these rights.

\section{Take down policy}

The Research Portal is Ulster University's institutional repository that provides access to Ulster's research outputs. Every effort has been made to ensure that content in the Research Portal does not infringe any person's rights, or applicable UK laws. If you discover content in the Research Portal that you believe breaches copyright or violates any law, please contact pure-support@ulster.ac.uk. 


\title{
Phthalocyanine-loaded nanostructured lipid carriers functionalized with folic acid for photodynamic therapy
}

\author{
João A. Oshiro-Junior ${ }^{\mathrm{a}, *}$, Mariana Rillo Sato ${ }^{\mathrm{b}}$, Fernanda Isadora Boni ${ }^{\mathrm{b}}$, \\ Karen Loraine Macena Santos ${ }^{\mathrm{a}}$, Kleber Thiago de Oliveira ${ }^{\mathrm{c}}$, Laura Marise de Freitas ${ }^{\mathrm{d}}$, \\ Carla Raquel Fontana ${ }^{\mathrm{d}}$, Dean Nicholas ${ }^{\mathrm{e}}$, Anthony McHale ${ }^{\mathrm{e}}$, John F. Callan ${ }^{\mathrm{e}}$, Marlus Chorilli ${ }^{\mathrm{a}, \mathrm{b}, *}$ \\ ${ }^{a}$ Graduation Program in Pharmaceutical Sciences, Center for Biological and Health Sciences, State University of Paraiba (UEPB), Campina Grande, PB, Brazil \\ b São Paulo State University (UNESP), School of Pharmaceutical Sciences, Araraquara, Department of Drugs and Medicines. Rodovia Araraquara-Jaú, km 1, Araraquara, \\ São Paulo, Brazil \\ ${ }^{\mathrm{c}}$ Departamento de Química, Universidade Federal de São Carlos, São Carlos, SP, Brazil \\ ${ }^{\mathrm{d}}$ São Paulo State University (UNESP), School of Pharmaceutical Sciences, Araraquara, Department of Clinical Analyses. Rodovia Araraquara-Jaú, km 1, Araraquara, São \\ Paulo, Brazil \\ ${ }^{\mathrm{e}}$ Biomedical Sciences Research Institute, University of Ulster, Coleraine, Northern Ireland, United Kingdom of Great Britain and Northern Ireland
}

\section{A R T I C L E I N F O}

\section{Keywords:}

Nanostructured lipid carriers

Functionalization

Folic acid

Phthalocyanines

Photodynamic therapy

Breast cancer

\begin{abstract}
A B S T R A C T
Breast cancer is a serious public health problem that causes thousands of deaths annually. Chemotherapy continues to play a central role in the management of breast cancer but is associated with extreme off-target toxicity. Therefore, treatments that directly target the tumor and display reduced susceptibility to resistance could improve the outcome and quality of life for patients suffering from this disease. Photodynamic therapy is a targeted treatment based on the use of light to activate a photosensitizer (PS) that then interacts with molecular oxygen and other biochemical substrates to generate cytotoxic levels of Reactive Oxygen Species. Currently approved PS also tends to have poor aqueous solubility that can cause problems when delivered intravenously. In order to circumvent this limitation, in this manuscript, we evaluate the potential of a phthalocyanine-loaded nanostructured lipid carrier (NLC) functionalized with folic acid (FA). To prepare the FA labelled NLC, the polymer PF127 was first esterified with FA and emulsified with an oil phase containing polyoxyethylene 40 stearate, capric/caprylic acid triglycerides, ethoxylated hydrogenated castor oil 40 and the PS zinc phthalocyanine. The resulting PS loaded FA-NLC had a hydrodynamic diameter of $180 \mathrm{~nm}$ and were stable in suspension for $>90$ days. Interestingly, the amount of singlet oxygen generated upon light activation for the PS loaded FANLC was substantially higher than the free PS, yet at a lower PS concentration. The PS was released from the NLC in a sustained manner with $4.13 \pm 0.58 \%$ and $27.7 \pm 3.16 \%$ after $30 \mathrm{~min}$ and 7 days, respectively. Finally, cytotoxicity assays showed that NLC in the concentrations of $09.1 \mu \mathrm{M}$ of PS present non-toxic with $>80 \pm 6.8 \%$ viable and after $90 \mathrm{~s}$ of the light-exposed the results show a statistically significant decrease in cell viability $(57 \pm 4 \%)$. The results obtained allow us to conclude that the functionalized NLC incorporated with PS associated with the PDT technique have characteristics that make them potential candidates for the alternative treatment of breast cancer.
\end{abstract}

\section{Introduction}

Innovative research is being focused on alternative strategies for the treatment of breast cancer, including the Photodynamic Therapy (PDT). PDT was approved for a number of clinical indications (Barret's esophagus, esophageal, endobronchial, and non-small cell lung cancers) by the FDA and has been tested to treat breast cancer in several studies, with promising results for controlling the recurrence rate [1,2].
PDT is based on oxidative photochemical reactions, requiring a photoactive compound, called photosensitizer (PS) and light of an appropriate wavelength [3]. This association (PS + light), in the presence of ground state oxygen, results in the generation of significant amounts of reactive oxygen species (ROS), including singlet oxygen, hydrogen peroxide $\left(\mathrm{H}_{2} \mathrm{O}_{2}\right)$ and hydroxyl radicals $(\cdot \mathrm{OH})$. These ROS induce multiple pathways of cellular and tissue damage, including DNA damage and membrane damage, that may lead to apoptosis or necrosis, and (but

\footnotetext{
* Corresponding authors.

E-mail addresses: joao.oshiro@pq.cnpq.br (J.A. Oshiro-Junior), marlus.chorilli@unesp.br (M. Chorilli).
} 
not limited to) vascular damage, compromising the tumor blood supply [4]. More importantly, the photodynamic reaction only takes place where the light is delivered, which makes PDT a highly selective therapy.

Therefore, unlike conventional cancer therapies (surgery, radiotherapy and chemotherapy), PDT is a minimally invasive therapy modality with minimum or no side effects; can be repeated without dose-limiting toxicity or inducible resistance; results in little or no scarring; can often be administered in the outpatient setting, and is not contraindicated with other therapy modalities [5].

Thus, hematoporphyrin derivatives (Photofrin $\mathrm{II}^{\circledR}$ ) were the first generation of PS; however, they exhibit low absorption in red light and cause skin photosensitivity as an adverse reaction. The use of secondgeneration PS such as the phthalocyanines bring numerous advantages to PDT, such as high purity and low toxicity, as well as high light absorption in the red region of the electromagnetic spectrum (the range in which light penetrates deeper into the tissue) [6,7]. However, these compounds are lipophilic molecules, which hinder their solubility in physiological medium and prevent the exploitation as potential PS [8].

In that sense, an attractive strategy to overcome these disadvantages is the incorporation of phthalocyanine PS into nanostructured lipid carriers (NLCs). NLCs are characterized by having a lipid matrix of imperfect crystals stabilized by surfactants, providing spaces for the incorporation of high concentrations of hydrophobic active substances [9]. In addition, its lipophilic properties result in better targeting towards the cancer cells [10].

The selectivity of the NLC for the tumor can be further improved by the functionalization of the carrier with a targeting moiety. Folic acid (FA) is commonly used for this purpose due to the difference in folate receptors expression between normal and tumor cells: the receptors are expressed in low amounts by healthy cells, and in large quantities by a variety of tumor cells (ovary, prostate and breast, for example) [11-13].

In this context, the use of FA-functionalized NLC as a PS carrier for PDT can be a promising nanobiotechnological tool for the treatment of tumors that overexpress the folate receptor, such as breast cancer. Hence, the aim of this study was to develop and characterize FAfunctionalized NLC carrying a second-generation PS (NLC-FA-PS) and to evaluate its photochemical and photodynamic properties for future applications in the treatment of breast cancer.

\section{Methods}

\subsection{Synthesis of PF127-FA}

The functionalization of synthetic polymer Pluronic F127 ${ }^{\circledR}$ (PF127) with FA was based on the synthesis developed by Lin et al. [14]. Initially, $87.58 \mathrm{mg}$ of FA (Mw $=441.404 \mathrm{~g} / \mathrm{mol}$, Sigma-Aldrich $)$ and $70.64 \mathrm{mg}$ of $1,1^{\prime}$-carbonyldiimidazole ( $\mathrm{Mw}=162.15 \mathrm{~g} / \mathrm{mol}$, Sigma-Aldrich (CDI)) were dissolved in $3 \mathrm{~mL}$ of dimethyl sulfoxide (DMSO) and added to a round bottom flask. The reaction remained under stirring (500 rpm) and inert atmosphere of $\mathrm{N}_{2}$ for $24 \mathrm{~h}$. Subsequently, $0.62 \mathrm{~g}$ of PF127 (Mw 12,500, Sigma), previously dried (overnight) in a vacuum oven, were added. The reaction was maintained under $\mathrm{N}_{2}$ atmosphere and stirred for $24 \mathrm{~h}$. The product was dialyzed in deionized water for 4 days using cellulose membrane (molecular weight cut-off $=14,000$, Sigma-Aldrich, $76 \mathrm{~mm}$ ). The water was changed every $3 \mathrm{~h}$. PF127-FA was recovered by lyophilization $(48 \mathrm{~h})$. All processes were carried out in the absence of light.

\subsection{Fourier transform infrared spectroscopy (FTIR)}

Bruker Vertex 70ATR infrared spectrometer using the $4 \mathrm{~cm}^{-1}$ resolution, with scan time of $64 \mathrm{~s}$, from 4000 to $400 \mathrm{~cm}^{-1}$ was used to perform Infrared spectrometric analysis of the FA, PF127 and PF127FA. Samples were diluted with $\mathrm{KBr}$, using $148 \mathrm{mg}$ of $\mathrm{KBr}$ and $2 \mathrm{mg}$ of the sample.

\subsection{Nuclear magnetic resonance (NMR)}

${ }^{1} \mathrm{H}$ NMR analysis of FA, PF127 and PF127-FA were recorded in deuterated dimethylsulfoxide (DMSO- $d_{6}$ ) using a Bruker Avance III 600 spectrometer, equipped with a $5 \mathrm{~mm}$ cryogenic probe.

\subsection{Quantification of FA content}

The efficacy of PF127-FA synthesis was performed following the methodologies previously described $[15,16]$. FA $(5 \mathrm{mg})$ was pre-dissolved in $10 \mathrm{~mL}$ of DMSO and then diluted in $40 \mathrm{~mL}$ of ultra-pure water to achieve a stock solution of $100 \mu \mathrm{g} / \mathrm{mL}$.

The detection was performed at $365 \mathrm{~nm}$ using a UV-visible spectrophotometer (Cary 60 UV-Vis, Agilent Technologies) and the standard curve with concentrations between 5 and $70 \mu \mathrm{g} / \mathrm{mL}$ was obtained. The value of the equation of the line was:

$y=0.0133 x-0.0185 R^{2}=0.9905$.

The content of folate conjugated to Pluronic F127 ${ }^{\circledR}$ was estimated based on the calibration curve of free FA, using the same UV-visible conditions, assuming a similar molar absorbance for the free FA and the conjugated molecule.

\subsection{Development of the NLC functionalized with FA}

The development of the NLC was based on the work conducted by SATO et al. [9], with modifications. Briefly, the selected formulation was composed of $2.07 \%(\mathrm{w} / \mathrm{w})$ polyoxyethylene 40 (EP) stearate, $2.05 \%(\mathrm{w} / \mathrm{w})$ capric/caprylic acid triglycerides (TGACC), and $0.88 \%$ $(\mathrm{w} / \mathrm{w})$ ethoxylated hydrogenated castor oil 40 , in the lipid phase, and $3.5 \%(\mathrm{w} / \mathrm{w})$ of PF127 functionalized with FA and deionized water in the aqueous phase. The aqueous phase was added onto the molten lipid phase under constant stirring, forming a pre-emulsion. The dispersion of the pre-emulsion was performed by sonication with an amplitude of $35 \%$, in discontinuous mode of 4 min with intervals of $30 \mathrm{~s}$ every $60 \mathrm{~s}$, $700 \mathrm{~W}$ of power and a probe of $1 / 16$ in diameter.

Subsequently, the formulations were centrifuged at $5000 \mathrm{rpm}$ for $10 \mathrm{~min}$ in order to verify their stability and eliminate the released titanium of the probe and the supernatant were packed in amber bottles and kept at $4{ }^{\circ} \mathrm{C}$.

The photosensitizer (Zinc 1,2,3,4,8,9,10,11,15,16,17,18,22,23,24,25hexadecafluoro-29H,31H-phthalocyanine) used in this study was commercially purchased from Sigma-Aldrich and added at the lipid phase with final concentration of $280 \mu \mathrm{M}$.

\subsection{Encapsulation efficiency determination}

PS-NLC obtained was centrifuged at $4800 \mathrm{rpm}$ for $30 \mathrm{~min}$. After, the supernatant was filtered $(0.45 \mu \mathrm{m})$, using cellulose acetate Minisart ${ }^{\circledR}$ NML filters to separate any non-encapsulated precipitate drug from encapsulated drug. The amount of PS loaded was quantified using Cary Eclipse Fluorescence Spectrophotometer at $677 \mathrm{~nm}$ with excitation at $639 \mathrm{~nm}$ (slit width of $5 \mathrm{~nm}$ ). The concentration of PS was calculated by means of a standard calibration curve derived for known concentrations of ZnPc (0.125-2 $\mu \mathrm{g} / \mathrm{mL})$. Thus, PS encapsulation efficiency was calculated as follows:

$\mathrm{EE}=\mathrm{M}_{1} / \mathrm{M}_{\mathrm{T}} \times 100$

where EE is the PS encapsulation efficiency, $\mathrm{M}_{1}$ the mass of PS in NLC, and $\mathrm{M}_{\mathrm{T}}$ the mass of PS used in the formulation [17].

\subsection{Hydrodynamic diameter (d.nm), polydispersity index (PDI) and zeta} potential (ZP) of FA-NLC

The average hydrodynamic diameter (d.nm), polydispersity index (PDI) and zeta potential (ZP) of the FA-NLC were performed by 
dynamic light scattering (DLS) and electrophoretic light scattering, at $25^{\circ} \mathrm{C}$, in a Zetasizer Nano NS equipment (Malvern Instruments, Malvern, UK). Samples were previously diluted in ultra-pure water $(1: 1000, v / v)$ for the analysis. Five measurements were performed for each analysis, and the results were expressed by the average of obtained values and the standard deviation. To check for the stability, formulations were analyzed at times intervals of $1,7,15,21,30,45,60$ and 90 days.

\subsection{Transmission electron microscopy (TEM)}

Transmission electron microscopy was performed using a JEOL JEM-100CX2 transmission electron microscope. The preparation of the sample consisted of adding a small aliquot in the nickel grate, followed by the removal of the excess sample by filter paper. The negative contraction was then performed by the addition of one drop of $1 \%(\mathrm{~m} /$ v) uranyl acetate solution in the sample. After $10 \mathrm{~min}$, the excess liquid was removed, and the sample was dried at room temperature. The samples were analyzed under a microscope at a voltage of $100 \mathrm{kV}$.

\subsection{Photobleaching}

PS samples (free PS dissolved in tetrahydrofuran; and NLC-FA-PS) were irradiated by a $660 \mathrm{~nm}$ LED device (IrradLED ${ }^{\circledR}$ — biopdi, Sao Carlos, SP, Brazil) using an irradiance of $100 \mathrm{~mW} / \mathrm{cm}^{2}$ and 1 -minute intervals, to a total of $10 \mathrm{~min}$. Between each irradiation the absorbance spectra of the samples were recorded (Synergy H1 Multi-Mode Reader, BioTek, Winooski, VT, USA).

\subsection{Singlet oxygen generation in cell free systems (SOSG)}

To a solution of SOSG $(2.5 \mu \mathrm{M})$ in methanol $(1.750 \mathrm{~mL})$ was added to the PS-NLC $(0.250 \mathrm{~mL}(0.125 \mathrm{mg}$ of PS)). The solution was exposed to light for $10 \mathrm{~min}$ (Fenix LD01 LED, $50 \mathrm{~mW}$ output, $113.0 \mathrm{~J} / \mathrm{cm}^{2}$ ) and the fluorescence intensity of SOSG (upon excitation at $505 \mathrm{~nm}$ ) was recorded at $525 \mathrm{~nm}$ at 5-minute intervals. The protocol was performed for the following groups (i) PS alone, (ii) PS + light, (iii) NLC-FA, (iv) NLCFA + light, (v) NLC-FA-PS and (vi) NLC-FA-PS + light.

\subsection{In vitro drug release studies}

The direct dialysis method was used for PS in vitro drug release studies. Aliquots of $1 \mathrm{~mL}$ of NLC containing PS were enclosed in SnakeSkin $^{\mathrm{TM}}$ Dialysis Tubing (Mw cut-off of 3500, Thermo Scientific, Rockford, USA) and dispersed in $50 \mathrm{~mL}$ of n-octanol (medium), maintained at $37^{\circ} \mathrm{C}$ and stirred with a magnetic stirrer at a constant rate of $500 \mathrm{rpm}$. At given time intervals, $700 \mu \mathrm{L}$ samples were withdrawn and the same amount of fresh medium was replaced. The released PS was quantified by fluorescence emission $\left(\lambda_{\mathrm{EX}}=639 \mathrm{~nm} ; \lambda_{\mathrm{EM}}=678 \mathrm{~nm}\right)$. The in vitro release profile was obtained by correlating time (h) versus drug release (\%). For comparison, the free PS was tested. For this, a PS mass was weighed and suspended in a small volume of medium, then the drug suspension was placed inside the dialysis pouch and the analysis performed as previously mentioned.

\subsection{MTT assay}

The breast cancer cell line MCF-7 was cultured in bottles with Dulbecco's Modified Eagle's Medium (DMEM) containing high glucose $(4.5 \mathrm{~g} / \mathrm{L})$ and supplemented with $10 \%$ fetal bovine serum and $1 \%$ of the penicillin-streptomycin mixture, maintained in a $5 \% \mathrm{CO}_{2}$ incubator at $37^{\circ} \mathrm{C}$ until the cell monolayer was confluent (70\%). The cells were then washed with $10 \mathrm{ml}$ of PBS solution and trypsinized, adding $5 \mathrm{ml}$ of ATV (Association of Trypsin $(0.2 \%)$ and Versene $(0.02 \%))$. The $100 \mu \mathrm{L}$ of cell suspension $\left(5 \times 10^{4}\right.$ cells $\left./ \mathrm{mL}\right)$ were seeded in 96 -well plates and after $24 \mathrm{~h}$ incubation, the medium was discarded and the cells were treated with a $100 \mu \mathrm{L}$ suspension of NLC-FA-PS in three different concentrations 9.1, 1.82 and $0.91 \mu \mathrm{M}$ of PS.

After $30 \mathrm{~min}$, selected wells were treated with light using an LED light source (Fenix LD01 LED, $50 \mathrm{~mW}$ output, $113.0 \mathrm{~J} / \mathrm{cm}^{2}$ ) and 4 treatment times (30, 60, 90 and $120 \mathrm{~s})$. Untreated cells and cells treated with light only were used for comparative purposes. After $24 \mathrm{~h}$, cellular metabolic activity was assessed using a MTT (4,5-dimethyl-2-thiazolyl) -2,5-diphenyl-2H-tetrazolium bromide (MTT, Sigma, USA) assay. Thus, the medium was discarded and $10 \mu \mathrm{L}$ of solution of PBS containing MTT $(5 \mathrm{mg} / \mathrm{mL})$ was added to each well and incubated at $37^{\circ} \mathrm{C}$, protected from light for $3 \mathrm{~h}$. Finally, $100 \mu \mathrm{L}$ of DMSO was added in each well and the spectrophotometric reading of the absorbance at wavelength $570 \mathrm{~nm}$ was performed on plate reader (FLUOstar Omega, BMG LABTECH).

\section{Results and discussions}

\subsection{Synthesis of PF127 with FA}

In the pre-formulation study for the NLC development, the PF127 was selected as the surfactant, based on its ability to sensitize multidrug-resistant cells which overexpress efflux proteins as P-glycoprotein and multidrug resistance-associated proteins [18]. As described previously, FA was chosen to increase the selectivity of the NLCs to ovarian, prostate and breast tumor cells. FA has high attraction for the cellular overexpressed receptor $\left(\mathrm{K}_{\mathrm{d}}=1 \mathrm{nM}\right)$, in addition, is a low cost, biocompatible and low molecular weight (441 Da) molecule. Those features allow for better diffusion through biological barriers (when compared to antibodies used in functionalization), and consequently, improves the internalization of molecules that would be naturally impermeable to the cell membrane via the endocytosis process $[19,20]$.

Previous studies focused on the synthesis of a compound of PF127 with FA demonstrated that at a molar ratio of 1:4, at least one of the two hydroxyl groups $(\mathrm{OH})$ present in PF127 was linked to the FA carboxylic acid group $(\mathrm{HO}-\mathrm{C}=\mathrm{O})$ by a covalent bond. In addition to providing a molecular targeting mechanism to FR positive cells, the covalent ester bond between PF127 and FA should also remain stable in circulation and only be hydrolyzed by endogenous esterase enzymes following cellular uptake [14].

The conjugation reaction involved first generating the active ester of FA (FA-DCI) using carbodiimide chemistry followed by addition of PF127 to form the ester between the FA and P127. Fig. S1 shows the schematic illustration of these reactions and an image of the material obtained, which was a yellow powder obtained in $54.18 \%$.

\subsection{Nuclear magnetic resonance and FTIR techniques}

To prove that the covalent ester bond between PF127 and FA was formed, infrared spectroscopy and nuclear magnetic resonance techniques were used.

\subsubsection{FTIR}

Fig. 1 shows the infrared spectra for PF127 and the product obtained from the reaction between PF127 and FA. It was possible to observe the presence of a band at $1720 \mathrm{~cm}^{-1}$, corresponding to the ester carbonyl stretch (R-COOR).

In addition, all bands of interest found for compound PF127-FA (522.23, 848.44, 954.32, 1124.82, 1287.54, 1345.15, 1467.38, $1605.19,1703.17,1971.88,2354.93$ and $2884.34 \mathrm{~cm}^{-1}$ ) are in accordance with the bands found in the work of Lin et al. [14].

The IR spectrum from FA is mainly characterized by the $\mathrm{C}=\mathrm{O}$ stretching vibrations $\left(1665 \mathrm{~cm}^{1}\right)$, the bending mode of the $\mathrm{N}-\mathrm{H}$ group $\left(1605 \mathrm{~cm}^{1}\right)$ and the absorption of the phenyl ring $\left(1460 \mathrm{~cm}^{1}\right)$.

Thus, through the infrared spectrometry technique, the formation of the product PF127-FA can be suggested, because unlike polymer (PF127), this compound has a characteristic band of the ester linkage. 


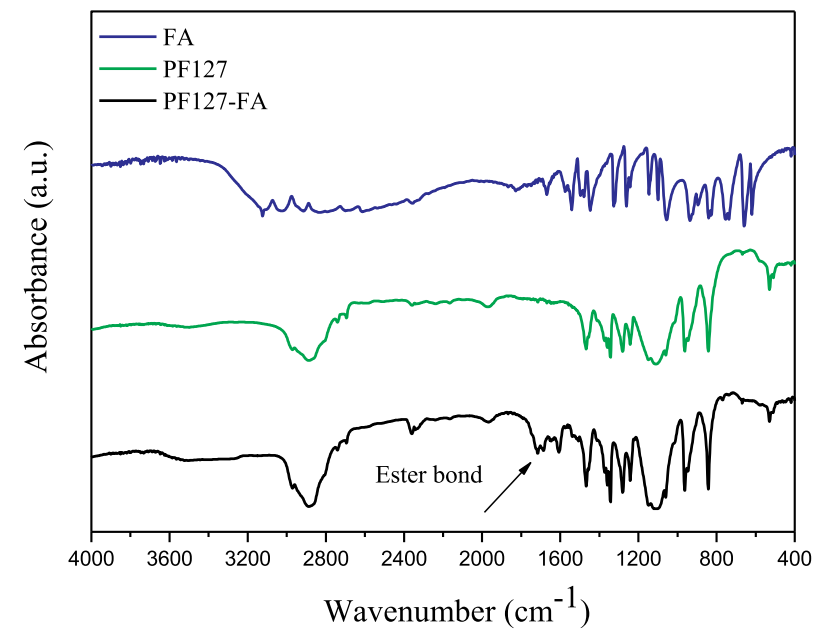

Fig. 1. Recorded infrared spectra of the product obtained from pure PF127, FA and from the reaction between FA and PF127.

\subsubsection{Nuclear magnetic resonance}

The ${ }^{1} \mathrm{H}$ NMR spectra of FA, the polymer PF127 and the synthesis product PF127-FA, are shown in Figs. S2, S3 and S4 available in supplementary information.

The ${ }^{1} \mathrm{H}$ NMR spectrum of the FA (S2) showed the characteristic signals of the aromatic ring protons $\delta$ 8.65-7.65 and the methylene protons at $\delta 4.47$. The broad residual peak at $\delta 3.33$ refers to the residual peak water in the sample.

For better understanding, a comparison of PF127-FA product data (S4) was done with the ${ }^{1} \mathrm{H}$ NMR data obtained by Lin et al. [14].

The comparison shows that the peaks are similar. In addition, we can identify the specific peaks of the clusters present in the isolated compounds. ${ }^{1} \mathrm{H}$ NMR analysis of the product was dominated by the large resonance at $3.5 \mathrm{ppm}$ attributed to the methylene protons of the POE block of the PF127 component. However, expansion of the aromatic region did reveal resonances attributed to the FA aromatic protons. Using a process of relative integration, and assuming an average molecular weight for PF127 of $\sim 12,500 \mathrm{Da}$, it was estimated that $69 \%$ of PF127 was labelled with FA and this is similar to that obtained by Lin et al. in previous studies [14].

\subsection{Folate determination in the conjugate PF127-FA}

FA concentration in the sample was $40 \mu \mathrm{g} / \mathrm{mL}$, the absorption was 0.075; consequently, based on the amount of FA in the beginning of the synthesis and in the yield of the process, for each $1 \mathrm{mg}$ of PF127, about $0.176 \mathrm{mg}$ of FA was conjugated. Therefore, based on the theoretical calculation, $77.03 \%$ of FA was linked to the reactive groups of the PF127.

\subsection{Preparation of the functionalized NLCs}

The preparation of the functionalized NLC was performed according to the methodology developed by Sato et al. [9]. These authors tested 20 formulations varying the concentration of PF127 in 1, 2, 2.5, 3, 3.5 and $4 \%$, dispersing the pre-emulsion by sonication with an amplitude of $8 \%$, in discontinuation mode of 20 min with interval of $30 \mathrm{~s}$. The results showed that all NLCs formed with $3.5 \%$ PF127 had a mean hydrodynamic diameter of $<112 \mathrm{~nm}$, and PDI of $<0.2$, indicating that the particles are homogeneously distributed (monodisperse).

However, high sonication times lead to greater contamination of the formulation by the metals of equipment [21]. Therefore, an amplitude of $35 \%$ and a time of $4 \mathrm{~min}$ were used in this work. The increase in the amplitude resulted in a superior increase of the probe temperature, obtaining particles in the nanometric scale and, consequently, the formation of a more homogeneous system [22].

Fig. S5 shows the visual characteristics for the NLC-FA with or without PS and illustrates its spatial distribution.

The NLC-FA exhibited well-defined macroscopic characteristics: yellow coloration, without precipitate, and no creaming process or phase separation occurs for as long as 90 days. The addition of PS (blue in color) causes a change in NLC coloration to green; however, stability of the macroscopic characteristics is maintained as observed for NLC without a drug.

\subsection{Incorporation of PS into NLCs and encapsulation efficiency determination}

The incorporation of PS into the NLC was performed concomitantly with the lipid phase preparation step. This method causes the retention and dispersion of the PS (hydrophobic character) within the lipid phase by hydrophobic-hydrophobic interactions.

It was possible to determine macroscopically that concentrations of PS $>280 \mu \mathrm{M}$ formed precipitates, thus it was not completely dispersed or solubilized into the NLC.

The formation of precipitates is a drawback of these photosensitizers, due to their hydrophobicity and tendency to aggregate in aqueous medium, which reduces their availability for ROS [23]. However, after the centrifugation and filtration procedures the encapsulation efficiency corresponded to $63.00 \pm 1.19 \%$ for formulation NLCFA.

The encapsulation efficiency can be considered high, since different nanosystems described in the literature (polymer nanoparticle, solid lipid nanoparticle, micelles, liposomes and others) are not able to solubilize and incorporate such amount of PS or hydrophilic molecules [24-26].

\subsection{Hydrodynamic diameter (Z-ave or d.nm), PDI and ZP of FA-NLC}

The physical stability of NLC depends on its size and ZP. In addition, NLC with nanometer size are advantageous for the treatment of tumors since solid tumors accumulate and retain particles between 100 and $780 \mathrm{~nm}$, a phenomenon denominated as enhanced permeability and retention (EPR) effect [27].

The results of d.nm, PDI and ZP of the NLC-FA and NLC-FA-PS are shown in Fig. 2.

The NLC-FA without PS produced values of d.nm from $152.2 \pm 0.97 \mathrm{~nm}$ to $166.7 \pm 1.33 \mathrm{~nm}$, with PDI values ranging from $0.21 \pm 0.0091$ to $0.14 \pm 0.018$ and $\mathrm{ZP}-17 \pm 1.18 \mathrm{mV}$ to $-16.4 \pm 0.45 \mathrm{mV}$ over the course of 90 days. Whereas, NLC-FA-PS produced values of d.nm from $165.3 \pm 2.34 \mathrm{~nm}$ to $181.3 \pm 0.99 \mathrm{~nm}$. For these samples, the PDI values range from $0.23 \pm 0.014$ to $0.18 \pm 0.012$ and $\mathrm{ZP}-17.3 \pm 0.74 \mathrm{mV}$ to $-19.9 \pm 1.32 \mathrm{mV}$ over the course of 90 days.

DLS results show that values of mean diameter, ZP and PDI were similar over the 90 days. In addition, the incorporation of PS in this concentration did not modify the distribution profile of d.nm, during the 90 days of storage, indicating homogeneity of the particles. The negative values of $\mathrm{ZP}$ are related to the ionization of $\mathrm{OH}$ or $\mathrm{COOH}$ groups present in the components used and are responsible for avoiding the nanoparticle agglomeration during storage time due to electrostatic repulsive forces [28]. The low values of standard deviation indicate a good reproducibility of the method.

Moreover, the results of mean diameter are similar to those found in the literature for NLC [9], thus the use of a larger amplitude (35\%) and a shorter sonication time ( $4 \mathrm{~min}$ ) has been shown to be effective.

\subsection{Transmission electronic microscopy (TEM)}

TEM is a technique used to verify the morphology and particle size at the nanoscale and is important to confirm the results of the DLS. 
(a) NLC-FA

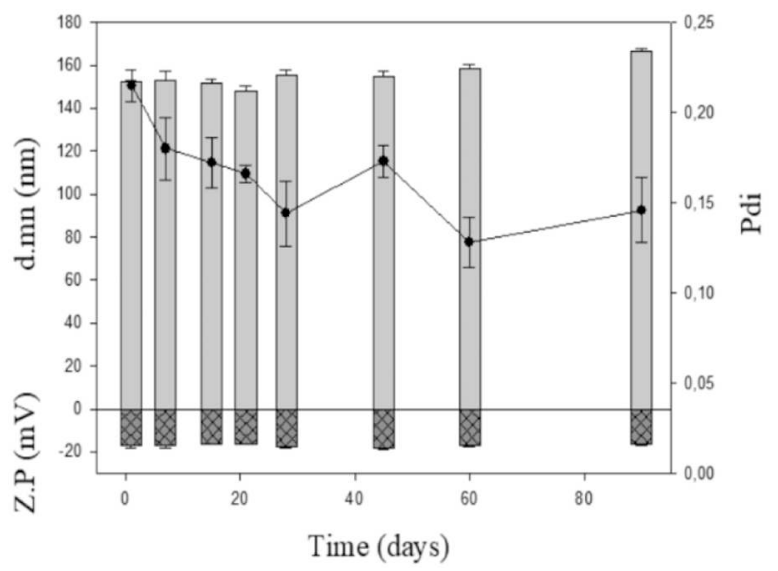

(b) NLC-FA-PS

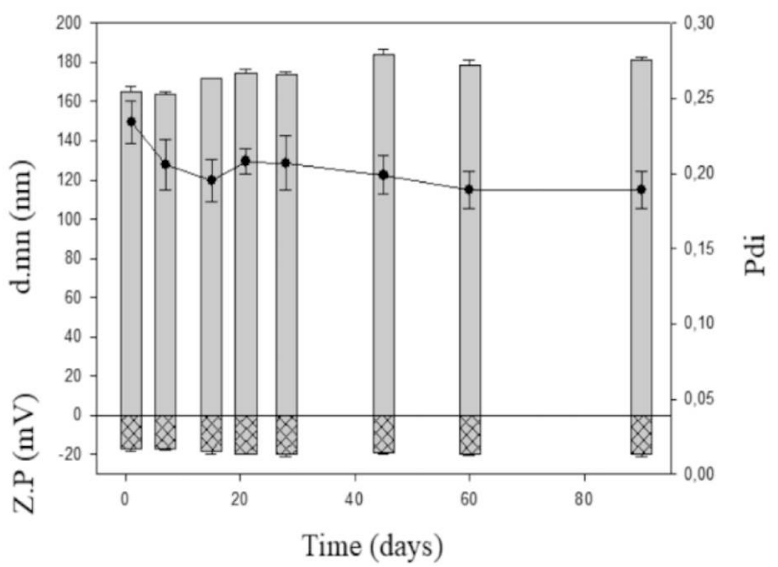

Fig. 2. Results of d.nm, PDI and ZP to NLC-FA (a) and NLC-FA-PS (b) directly after preparation and after 7, $15,21,30,45,60$ and 90 days, $n=3$.

The results of TEM reveal that NLC-FA (Fig. 3a) and NLC-FA-PS (Fig. 3b) have spherical morphology with nanometer sizes between 50 and $300 \mathrm{~nm}$, similar to the sizes found in the DLS particle distribution graph.

Moreover, by analyzing the amplified NLC-FA-PS particle, it was possible to observe the incorporation of the PS by means of the dark contracture caused by the metal present in the PS, as mentioned in the step of incorporation, PS (liposoluble) by hydrophobic/hydrophobic bond would be dispersed in the imperfect crystals of the lipid matrix.

\subsection{Photobleaching}

It is important that the nanosystem does not interfere with the PS photobleaching profile. If the nanosystem increases the photobleaching rate, then the PS will not be available long enough after light activation, reducing its efficiency in generating ROS. Otherwise, a higher concentration of the PS would be necessary to be administered to compensate for the loss [29].

Fig. 4 shows the photobleaching rate of the pure PS (THF solution) and all the nanosystems. The PS concentration in all samples was $500 \mu \mathrm{g} / \mathrm{mL}$. It is clear that the final formulation, NLC-FA-PS, protected the PS from photobleaching, an important feature to guarantee efficient photodynamic reactions.

Free PS spectrum (Fig. 4a) showed after 2 min a rapid decrease in the absorbance intensity when exposed to light at $671 \mathrm{~nm}$. After $6 \mathrm{~min}$ of irradiation, a $56 \%$ decrease was observed but then remained relatively stable, whereas when incorporated into the NLC-FA, the photobleaching rate was reduced to $25 \%$ after $6 \mathrm{~min}$. These results demonstrate that the incorporation of PS in NLC not only reduced the photobleaching rate but it also enables its dispersion in aqueous buffer.

\subsection{SOSG results}

Singlet oxygen production is related to the photodynamic activity. Thus, singlet oxygen production was estimated via SOSG assay to verify if the PS-loaded in NLC could modify the singlet oxygen production in relation to the free PS. SOSG is non-fluorescent but when bleached by singlet oxygen produces a fluorescent substrate. The results of percentage increase in fluoresce intensity of SOSG are shown in Fig. 5.

Free PS and NLC-FA-PS produced the same increase in percentage of SOSG emission until $10 \mathrm{~min}, 63.34 \% \pm 8.05$ and $61.89 \% \pm 2.25$, respectively and significant increase in relation to PS and NLC-FA-PS without light. The NLC-FA with or without light does not show any increase in SOSG emission.

\subsection{In vitro drug release studies}

The use of n-octanol was necessary to ensure sink conditions, since the PS is extremely insoluble in water. This medium was adapted from previous publications and it has similarity to lipophilicity of biological membranes [30,31]. Pure PS was used as control for comparisons in the release profile aiming to understand the dose released from the nanoparticle (Fig. 6).

The results reveal that NLC-FA did not reveal a burst effect but exhibited a sustained release of the PS showing $4.13 \pm 0.58 \%$ and $27.7 \pm 3.16 \%$ after $30 \mathrm{~min}$ and 7 days, respectively; whereas, free PS exhibited $32.09 \pm 4.13 \%$ and $83.66 \pm 6.9 \%$ of drug release, after $30 \mathrm{~min}$ and $24 \mathrm{~h}$, respectively. This behavior can be associated with NLC which are composed of a mixture of liquid and solid lipids forming imperfect crystalline structures, which results in larger drug incorporation spaces, and better incorporation efficiency compared to other nanosystems, preventing its expulsion. Moreover, the sustained
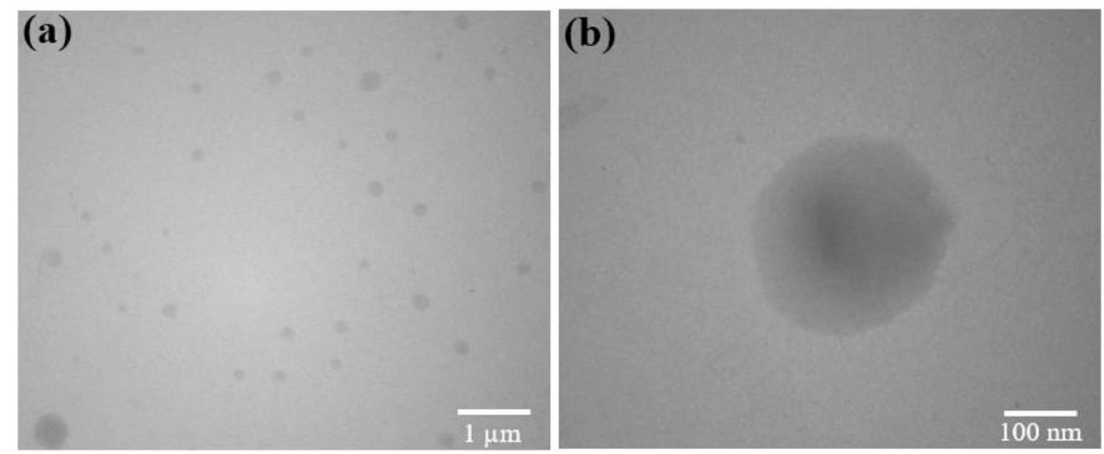

Fig. 3. TEM images of the nanocarriers (a) NLC-FA and (b) NLC-FA-PS, at magnification of 20,000 $\times$ and 100,000 $\times$, respectively. 

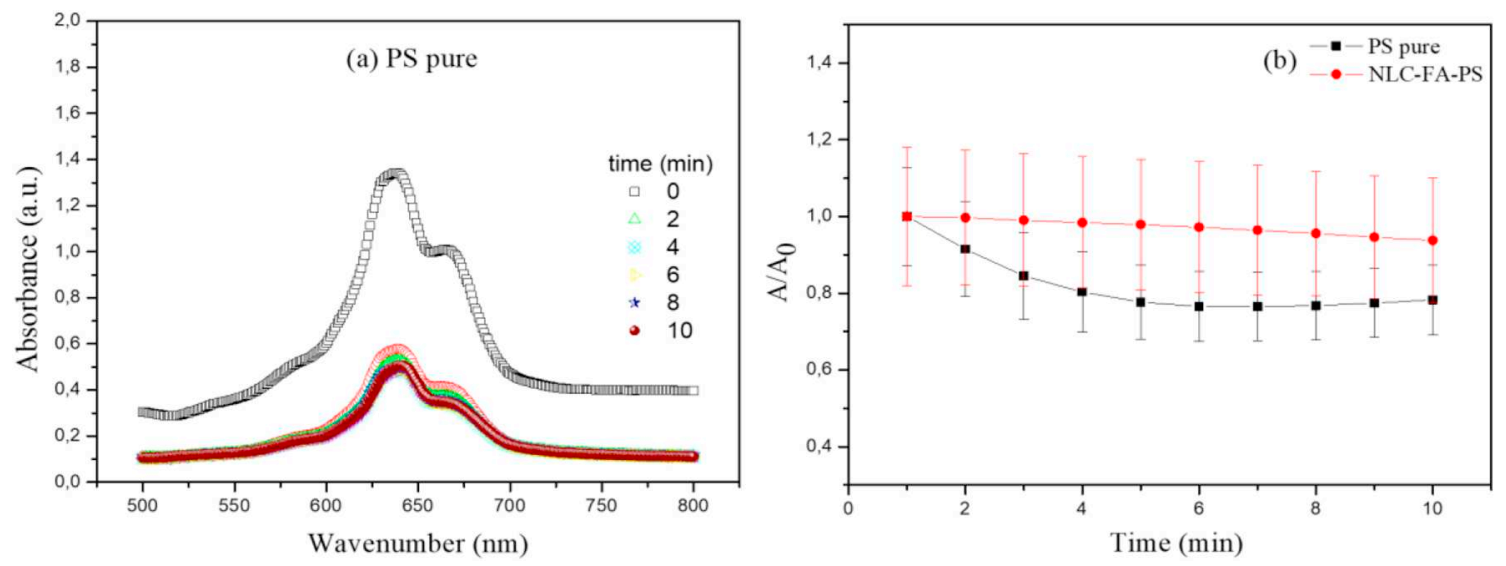

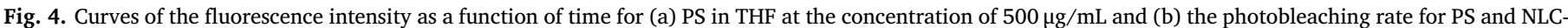
FA-PS.

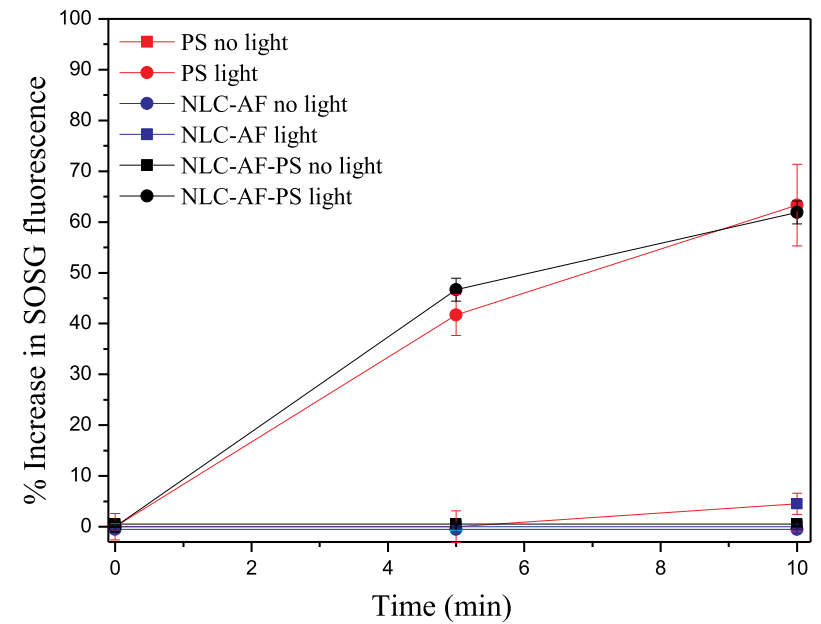

Fig. 5. Curves of the percentage increase in SOSG emission as a function of time for PS, NLC-AF and NLC-AF-PS after different treatments: in the dark as a control (no light), and after LED light $\left(50 \mathrm{~mW}\right.$ output, $\left.113.0 \mathrm{~J} / \mathrm{cm}^{2}\right)$. Error bars represent \pm the standard error where $n=3$.

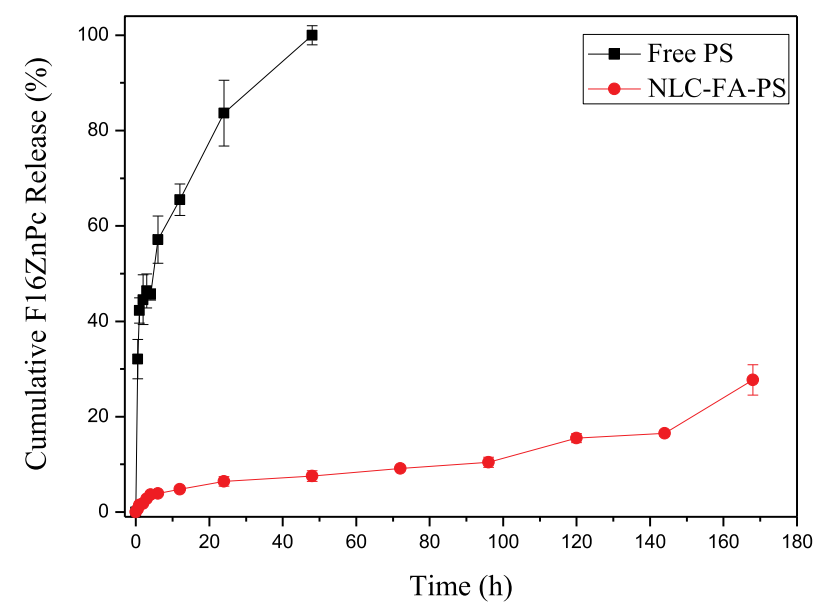

Fig. 6. In vitro drug release profiles of free PS and NLC-FA-PS. The experiments were performed in n-octanol at $37^{\circ} \mathrm{C}$.

release, in combination with the higher resistance to photobleaching, means there is potential for one administration of the PS loaded NLC-FA to be used for multiple treatments [32].

\subsection{MTT assay}

Cytotoxicity assays are highly utilized since they reduce the need for laboratory animals, provide a quick indication of efficacy and are low cost.

Fig. 7 shows the plot of cell viability (\%) for MCF-7 cells line following treatment with (i) untreated, (ii) light only, (iii) NLC-FA, (iv) NLC-FA-PS in three different concentrations $(0.91,1.82$ and $9.1 \mu \mathrm{M})$ without light, (v) NLC-FA-PS $(0.91 \mu \mathrm{M})$ in four different light exposure times(30, 60, 90 and $120 \mathrm{~s})$.

First, we investigated the NLC-FA-PS on MCF-7 cell viability in the three concentrations of $0.91,1.82$ and $9.1 \mu \mathrm{M}$ in absence of light. The results showed that until $0.91 \mu \mathrm{M}$ they are non-toxic with $>80 \pm$ $6.8 \%$ viable. When NLC-FA-PS $(0.91 \mu \mathrm{M})$ was irradiated for $120 \mathrm{~s}$, the viability decreases to $57 \pm 4 \%$ which was statistically significant (Fig. 7).

\section{Conclusion}

With this research, it was possible to conclude that the synthesis

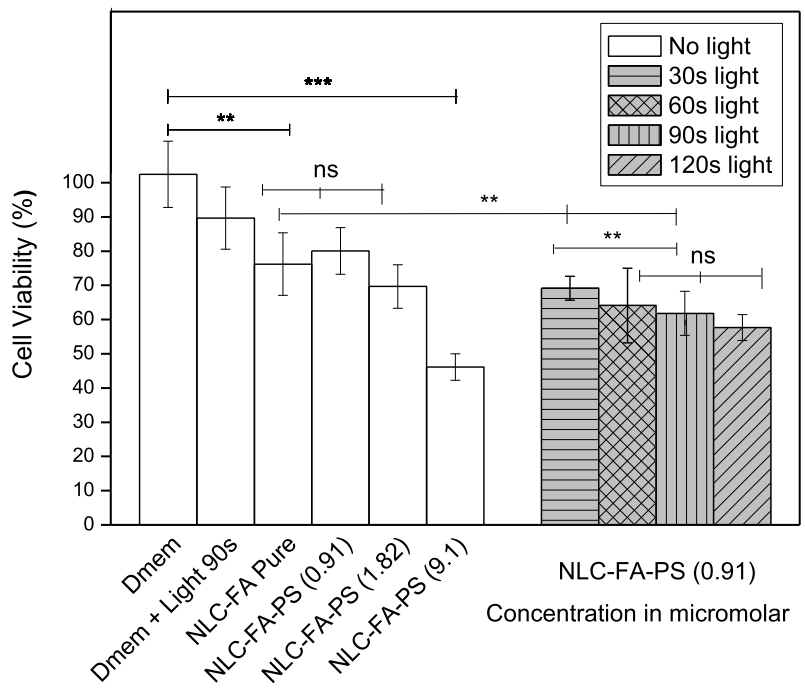

Fig. 7. Plot of cell viability (\%) for MCF-7 cells line following treatment with (i) untreated, (ii) light only, (iii) NLC-FA, (iv) NLC-FA-PS in three different concentrations (0.91, 1.82 and $9.1 \mu \mathrm{M})$ without light, (v) NLC-FA-PS $(0.91 \mu \mathrm{M})$ in four different times of exposure to light $(30,60,90$ and $120 \mathrm{~s}) .{ }^{*} p<0.05$, $* * p<0.01, * * * p<0.001$, ns: no significant difference. Error bars represent \pm the standard error, $n=3$. 
between FA and PF127 was performed efficiently. Subsequently, using this molecule, it was possible to develop a new PS loaded NLC with a mean size of $<180 \mathrm{~nm}$ which is ideal to passive target in tumors by EPR effect. In addition, the PS chosen has high light absorption in the red region. The light penetration in the tissues is directly proportional to its wavelength $(\lambda)$ reaching up to $16.0 \mathrm{~mm}$ at $\lambda$ from 700 to $900 \mathrm{~nm}$. Thus, the treatment could be conducted for tumors within this depth without microsurgery for light probe introduction. Besides that, the sustained release showed the potential for one administration of the PS loaded NLC-FA to be used for multiple treatments. Finally, the photobleaching results did not alter the photobleaching profile of PS, whereas NLC exerted a protective effect on PS, so it is possible to use a smaller amount of drug producing high concentrations of ROS. MTT assay showed that NLC in the concentrations of $0.91 \mu \mathrm{M}$ of PS presented a significant reduction after $90 \mathrm{~s}$ of the light-exposed in cell viability (57 $\pm 4 \%$ ). The results obtained allow us to conclude that the functionalized NLC incorporated with PS associated with the PDT technique have characteristics that make them potential candidates for the alternative treatment of breast cancer.

\section{Acknowledgements}

This study was financed in part by the Coordenação de Aperfeiçoamento de Pessoal de Nível Superior - Brasil (CAPES) Finance Code 001. This study is part of the National Institute of Science and Technology in Pharmaceutical Nanotechnology: a transdisciplinary approach INCT-NANOFARMA, which is supported by São Paulo Research Foundation (FAPESP, Brazil) Grant \#2014/50928-2, and by "Conselho Nacional de Desenvolvimento Científico e Tecnológico" (CNPq, Brazil) Grant \# 465687/2014-8. FAPESP Grant \# 2018/175737 and 2016/11198-4 and Ulster University.

\section{Appendix A. Supplementary data}

Supplementary data to this article can be found online at https:// doi.org/10.1016/j.msec.2019.110462.

\section{References}

[1] A. Dimofte, T.C. Zhu, S.M. Hahn, R.A. Lustig, In vivo light dosimetry for motexafin lutetium-mediated PDT of recurrent breast cancer, Lasers Surg. Med. 31 (2002) 305-312, https://doi.org/10.1002/1sm.10115.

[2] M. Sun, C. Zhou, H. Zeng, N. Puebla-Osorio, E. Damiani, J. Chen, et al., Hiporfinmediated photodynamic therapy in preclinical treatment of osteosarcoma, Photochem. Photobiol. 91 (2015) 533-544, https://doi.org/10.1111/php.12424.

[3] G. Zheng, J. Chen, K. Stefflova, M. Jarvi, H. Li, B.C. Wilson, Photodynamic molecular beacon as an activatable photosensitizer based on protease-controlled singlet oxygen quenching and activation, Proc. Natl. Acad. Sci. U. S. A. 104 (2007) 8989-8994, https://doi.org/10.1073/pnas.0611142104.

[4] W.C. Huang, M.Y. Shen, H.H. Chen, S.C. Lin, W.H. Chiang, P.H. Wu, et al., Monocytic delivery of therapeutic oxygen bubbles for dual-modality treatment of tumor hypoxia, J. Control. Release 220 (2015) 738-750, https://doi.org/10.1016/j. jconrel.2015.09.016.

[5] J. Liu, Y. Huang, A. Kumar, A. Tan, S. Jin, A. Mozhi, et al., pH-Sensitive nanosystems for drug delivery in cancer therapy, Biotechnol. Adv. 32 (2014) 693-710, https://doi.org/10.1016/j.biotechadv.2013.11.009.

[6] P.E.P. Farias, D.N.B. Felipucci, A.R. Simioni, F.L. Primo, A.C. Tedesco, L.A. Salata, Effects of photodynamic process (PDP) in implant osseointegration: a histologic and histometric study in dogs, Clin. Implant. Dent. Relat. Res. 17 (2015) 879-890, https://doi.org/10.1111/cid.12204.

[7] D.C. Zancanela, F.L. Primo, A.L. Rosa, P. Ciancaglini, A.C. Tedesco, The effect of photosensitizer drugs and light stimulation on osteoblast growth, Photomed. Laser Surg. 29 (2011) 699-705, https://doi.org/10.1089/pho.2010.2929.

[8] F.C. Rossetti, M.C.A. Fantini, A.R.H. Carollo, A.C. Tedesco, M.V. Lopes Badra Bentley, Analysis of liquid crystalline nanoparticles by small angle X-ray diffraction: evaluation of drug and pharmaceutical additives influence on the internal structure, J. Pharm. Sci. 100 (2011) 2849-2857, https://doi.org/10.1002/jps.22522.

[9] M.R. Sato, J.A. Oshiro Junior, R.T. Machado, P. C. Souza de, D. L. Campos, F. Pavan, et al. nanostructured lipid carriers for incorporation of copper (II) complexes to be used against Mycobacterium tuberculosis, Drug. Des. Devel. Ther. (2017) 909-921, https://doi.org/10.2147/DDDT.S127048.

[10] J.C.O. Sardi, L. Scorzoni, T. Bernardi, A.M. Fusco-Almeida, M.J.S. Mendes Giannini, Candida species: current epidemiology, pathogenicity, biofilm formation, natural antifungal products and new therapeutic options, J. Med. Microbiol. 62 (2013) 10-24, https://doi.org/10.1099/jmm.0.045054-0.

[11] T. Asai, Nanoparticle-mediated delivery of anticancer agents to tumor angiogenic vessels, Biol. Pharm. Bull. 35 (2012) 1855-1861, https://doi.org/10.1248/bpb. b212013.

[12] H. Meng, J.Y. Chen, L. Mi, P.N. Wang, M.Y. Ge, Y. Yue, et al., Conjugates of folic acids with BSA-coated quantum dots for cancer cell targeting and imaging by singlephoton and two-photon excitation, J. Biol. Inorg. Chem. 16 (2011) 117-123, https://doi.org/10.1007/s00775-010-0709-z.

[13] C. Zhou, H. Shen, Y. Guo, L. Xu, J. Niu, Z. Zhang, et al., A versatile method for the preparation of water-soluble amphiphilic oligomer-coated semiconductor quantum dots with high fluorescence and stability, J. Colloid Interface Sci. 344 (2010) 279-285, https://doi.org/10.1016/j.jcis.2010.01.015.

[14] J.J. Lin, J.S. Chen, S.J. Huang, J.H. Ko, Y.M. Wang, T.L. Chen, et al., Folic acidPluronic F127 magnetic nanoparticle clusters for combined targeting, diagnosis, and therapy applications, Biomaterials 30 (2009) 5114-5124, https://doi.org/10. 1016/j.biomaterials.2009.06.004.

[15] Y. Zhang, J. Li, M. Lang, X. Tang, L. Li, X. Shen, Folate-functionalized nanoparticles for controlled 5-fluorouracil delivery, J. Colloid Interface Sci. 354 (2011) 202-209.

[16] L. Wang, M. Li, N. Zhang, Folate-targeted docetaxel-lipid-based-nanosuspensions for active-targeted cancer therapy, Int. J. Nanomedicine 7 (2012) 3281-3294.

[17] Maha Fadel, Kawser Kassab, Doa Abdel Fadeel, Zinc phthalocyanine-loaded PLGA biodegradable nanoparticles for photodynamic therapy in tumor-bearing mice, Lasers Med. Sci. 25 (2010) 283-292, https://doi.org/10.1007/s10103-009-0740-x.

[18] A.V. Kabanov, E.V. Batrakova, V.Y. Alakhov, Pluronic (R) block copolymers as novel polymer therapeutics for drug and gene delivery, J. Control. Release 82 (2002) 189-212, https://doi.org/10.1016/s0168-3659(02)00009-3.

[19] G. Sahay, D.Y. Alakhova, A.V. Kabanov, Endocytosis of nanomedicine, J. Control. Release 145 (2010) 182-195, https://doi.org/10.1016/j.jconrel.2010.01.036. Endocytosis.

[20] B. Stella, S. Arpicco, M.T. Peracchia, D. Desmaële, J. Hoebeke, M. Renoir, et al., Design of folic acid-conjugated nanoparticles for drug targeting, J. Pharm. Sci. 89 (2000) 1452-1464, https://doi.org/10.1002/1520-6017(200011) 89:11<1452::AID-JPS8 > 3.0.CO;2-P.

[21] R. R. Agayan, T. Horvath, B. H. McNaughton, J. N. Anker, R. Kopelman. Optical manipulation of metal-silica hybrid nanoparticles (2004) 502. doi:https://doi.org/ $10.1117 / 12.559757$.

[22] T. Kaur, R. Slavcev, Solid lipid nanoparticles: tuneable anti-cancer gene/drug delivery systems, Nov. Gene Ther. Approaches (2013) 53-73, https://doi.org/10. 5772/54781.

[23] D. Bechet, P. Couleaud, C. Frochot, M.L. Viriot, F. Guillemin, M. Barberi-Heyob, Nanoparticles as vehicles for delivery of photodynamic therapy agents, Trends Biotechnol. 26 (2008) 612-621, https://doi.org/10.1016/j.tibtech.2008.07.007.

[24] A.M. Lima, C.D. Pizzol, F.B.F. Monteiro, T.B. Creczynski-Pasa, G.P. Andrade, A.O. Ribeiro, et al., Hypericin encapsulated in solid lipid nanoparticles: phototoxicity and photodynamic efficiency, J. Photochem. Photobiol. B Biol. 125 (2013) 146-154, https://doi.org/10.1016/j.jphotobiol.2013.05.010.

[25] P.J. Rao, H. Khanum, A green chemistry approach for nanoencapsulation of bioactive compound - Curcumin, LWT Food Sci. Technol. 65 (2016) 695-702, https://doi.org/10.1016/j.lwt.2015.08.070.

[26] J.S. An, J.E. Kim, D.H. Lee, B.Y. Kim, S. Cho, I.H. Kwon, et al., 0.5\% Liposomeencapsulated 5-aminolevulinic acid (ALA) photodynamic therapy for acne treatment, J. Cosmet. Laser Ther. 13 (2011) 28-32, https://doi.org/10.3109/14764172. 2011.552613.

[27] U. Bazylińska, R. Frąckowiak, Z. Brzózka, K.A. Wilk, The effect of anionic dicephalic surfactants on fabrication of varied-core nanocarriers for sustained release of porphyrin photosensitizers, J. Photochem. Photobiol. B Biol. 166 (2017) 169-179, https://doi.org/10.1016/j.jphotobiol.2016.11.012.

[28] T. Varadavenkatesan, R. Vinayagam, R. Selvaraj, Structural characterization of silver nanoparticles phyto-mediated by a plant waste, seed hull of Vigna mungo and their biological applications, J. Mol. Struct. 1147 (2017) 629-635, https://doi.org/ 10.1016/j.molstruc.2017.07.002

[29] L.M. Ronchi, A. Verónica, F. Nardy, A. Romero, G.L. Sena De, R.A. Jorge, et al., Influência Da Agregação E Do Fotobranqueamento Na Atividade Fotodinâmica De Protoporfirina, Rev. Capixaba Ciência e Tecnol. (2007) 5-12.

[30] C.S. Paula, A.C. Tedesco, F.L. Primo, J.M.C. Vilela, Margareth Spangler Andrade, Vanessa Carla Furtado Mosqueira, Chloroaluminium phthalocyanine polymeric nanoparticles as photosensitisers: photophysical and physicochemical characterisation, release and phototoxicity in vitro, Eur. J. Pharm. Sci. 49 (2013) 371-381.

[31] M. Chorny, I. Fishbein, H.D. Danenberg, G. Golomb, Study of the drug release mechanism from tyrphostin AG-1295 loaded nanospheres by in situ and external sink methods, J. Control. Release 83 (2002) 401-414.

[32] P. Ghasemiyeh, S. Mohammadi-Samani, Solid lipid nanoparticles and nanostructured lipid carriers as novel drug delivery systems: applications, advantages and disadvantages, Res. Pharm. Sci. 13 (4) (2018 Aug) 288-303, https://doi.org/10. 4103/1735-5362.235156. 